colleagues. With regard to the use of statins, in a previous study we reported on their potential role in decreasing pneumonia severity [3], and we agree that differences in statin and other drug use may have caused some unmeasured confounding in our study.

The issue of obesity and infection in general is complicated. A certain degree of mild obesity or being slightly overweight might even be beneficial to withstanding infection [4] or when admitted with critical disease to the intensive care unit [5]. Based on our own results and those of others, including those noted during the recent influenza A (H1N1) pandemic, we believe that severe obesity (perhaps in particular abdominal obesity) increases the risk of severe influenza and pneumonia, as also reflected in the current immunisation guidelines [6]. We believe there is less evidence that mild obesity or being slightly overweight predicts severe respiratory tract infections, particularly where it is not associated with obesity-related comorbidities such as cardiovascular disease or diabetes [1].

We wholeheartedly agree with the remarks by I. Schreter and colleagues that, given the globally rising prevalence of obesity, we need to improve our understanding of the biological association between obesity and infections. This task requires joint efforts from epidemiologists and clinical and laboratory researchers within endocrinology, infectious diseases, respiratory medicine and related specialties.

R.W. Thomsen*, J.B. Kornum*, M. Nørgaard*, C. Dethlefsen ${ }^{\# \text {, }}$ K.M. Due ${ }^{\#}$, A. Tjønneland ${ }^{ף}$, H.T. Sørensen* and K. Overvad*\#+

*Dept of Clinical Epidemiology, Institute of Clinical Medicine, Aarhus University Hospital, "Dept of Clinical Epidemiology,
Center for Cardiovascular Research, Aalborg Hospital, ${ }^{+}$Dept of Cardiology, Aalborg Hospital, Aarhus University Hospital, Aarhus, and "Danish Cancer Society, Copenhagen, Denmark.

Correspondence: R.W. Thomsen, Dept of Clinical Epidemiology, Institute of Clinical Medicine, Aarhus University Hospital, Aarhus, Denmark. E-mail: r.thomsen@rn.dk

Statement of Interest: None declared.

\section{REFERENCES}

1 Kornum JB, Nørgaard M, Dethlefsen C, et al. Obesity and risk of subsequent hospitalisation with pneumonia. Eur Respir J 2010; 36: 1330-1336.

2 Kornum JB, Thomsen RW, Riis A, et al. Diabetes, glycemic control, and risk of hospitalization with pneumonia: a population-based case-control study. Diabetes Care 2008; 31: 1541-1545.

3 Thomsen RW, Riis A, Kornum JB, et al. Preadmission use of statins and outcomes after hospitalization with pneumonia: populationbased cohort study of 29,900 patients. Arch Intern Med 2008; 168: 2081-2087.

4 Leung CC, Lam TH, Chan WM, et al. Lower risk of tuberculosis in obesity. Arch Intern Med 2007; 167: 1297-1304.

5 Akinnusi ME, Pineda LA, El Solh AA. Effect of obesity on intensive care morbidity and mortality: a meta-analysis. Crit Care Med 2008; 36: $151-158$

6 Fiore AE, Uyeki TM, Broder K, et al. Prevention and control of influenza with vaccines: recommendations of the Advisory Committee on Immunization Practices (ACIP), 2010. MMWR Recomm Rep 2010; 59: 1-62.

\title{
The effect of nanoparticles on airway allergy in mice
}

\section{To the Editors:}

We read with great interest a recent experimental (in vivo) study by HuSSAIN et al. [1] and would like to comment on that article. First of all, we were very interested in the overall results that a single airway exposure to relatively low dose $\left(16 \mu \mathrm{g} \cdot \mathrm{mouse}^{-1}\right)$ of nanoparticles facilitates allergic airway inflammation. We have previously examined several types of nanoparticles/nanomaterials on ovalbumin-induced airway inflammation [2-5]. However, the doses were higher (25$100 \mu \mathrm{g} \cdot$ mouse $^{-1}$ administered weekly a total of seven times) and provoked a more moderate increase in the number of inflammatory leukocytes into bronchoalveolar spaces in the absence of allergen than that in the present study by HUSSAIN et al. [1]. Thus, their study is valuable in terms of promoting the effect of relatively realistic dose of nanoparticles on allergic inflammation, although sensitivity against nanoparticles seems to depend on mouse strains (we used ICR mice). We have recently shown that single intratracheal instillation of carbon black nanoparticles (CBNPs) $(14 \mathrm{~nm})$ at a dose of $10 \mu \mathrm{g} \cdot$ mouse $^{-1}$ aggravates bleomycin-induced pulmonary fibrosis (unpublished data); thus, taking these studies into consideration, it is confirmed at the animal model (in vivo) level that exposure to trace doses of some nanoparticles exacerbates several types of pulmonary inflammatory conditions.

Consistent with the study by HuSSAIN et al. [1], we have found that effects of nanoparticles/nanomaterials on airway hyperresposiveness depend on the characteristics of these materials: two sizes (14 and $56 \mathrm{~nm}$ ) of carbon nanoparticles significantly enhanced airway resistance [2]; in contrast, two types (singleand multiwalled) of carbon nanotubes $[3,4]$ and two sizes $(25$ and $100 \mathrm{~nm}$ ) of latex nanoparticles did not ([5] and unpublished data). Indeed, some previous reports have implicated the independency of airway hyperresponsiveness from airway inflammation $[6,7]$; thus, the theory might be applied to the impacts of nanoparticles/nanomaterials on the allergic trait in the study by HUSSAIN et al. [1].

Regarding factors contributing to inflammatory cell infiltration in the airway, impacts of immune modulators on the T-helper cell (Th) milieu should be important to assess allergic reactions. In particular, Th2 (e.g. interleukin (IL)-5) and Th17 (e.g. IL-17A) cytokines are reportedly crucial for eosinophil 
maturation, activation, survival and migration, and neutrophil invasion, respectively [8]. Measurement of the levels in the lung (brochoalveolar lavage supernatants and/or lung homogenates) warrants further information about the effects of nanoparticles on allergic pathophysiology. Alternatively, the nanoparticles may preferentially affect other chemotactic factors for leukocytes, such as eotaxin, RANTES (regulated on activation, normal T-cell expressed and secreted), anaphylatoxins and lipid mediators, and/or their producing cells.

Finally, as Hussain et al. [1] described in their discussion, the effects of nanoparticles/nanomaterials on the phenotype and function of dendritic cells (DCs), as immune initiators, should be important for subsequent allergic pathology. Likewise, the degree of the effects appears to depend on the materials. We have also examined the effects of several environmental toxicants on bone marrow-derived DCs: CBNPs [9, 10], carbon nanotubes [3, 4], di(2-ethylhexyl)-phthalate [11] and diisononyl-phthalate [12] activated DCs in vitro and in vivo, whereas latex nanoparticles did not (unpublished data). Interestingly, we have confirmed that the effects on DCs and antigen-presenting cells (APCs) parallel those on allergic pathology in vivo in their overall trend [12]. Therefore, we propose that the enhancing effects of nanoparticles on the allergic asthma examined by HUSSAIN et al. [1] are mediated via the inappropriate activation of APCs, including DCs.

\section{K-I. Inoue* and H. Takano"}

*School of Pharmacy, Kitasato University, Tokyo, and "National Institute for Environmental Studies, Tsukuba, Japan.

Correspondence: K-I. Inoue, Dept of Public Health and Molecular Toxicology, School of Pharmacy, Kitasato University, 5-9-1 Shirokane, Minato-ku, Tokyo 108-8641, Japan. E-mail: inouek@pharm.kitasato-u.ac.jp

Statement of Interest: None declared.

\section{REFERENCES}

1 Hussain S, Vanoirbeek JA, Luyts K, et al. Lung exposure to nanoparticles modulates an asthmatic response in a mouse model. Eur Respir J 2010; 37: 299-309.

2 Inoue $\mathrm{K}$, Takano H, Yanagisawa R, et al. Effects of nanoparticles on lung physiology in the presence or absence of antigen. Int $J$ Immunopathol Pharmacol 2007; 20: 737-744.

3 Inoue K, Koike E, Yanagisawa R, et al. Effects of multi-walled carbon nanotubes on a murine allergic airway inflammation model. Toxicol Appl Pharmacol 2009; 237: 306-316.

4 Inoue K, Yanagisawa R, Koike E, et al. Repeated pulmonary exposure to single-walled carbon nanotubes exacerbates allergic inflammation of the airway: possible role of oxidative stress. Free Radic Biol Med 2010; 48: 924-934.

5 Inoue $\mathrm{K}$, Takano $\mathrm{H}$, Yanagisawa $\mathrm{R}$, et al. Size effects of latex nanomaterials on lung inflammation in mice. Toxicol Appl Pharmacol 2009; 234: 68-76.

6 Cockcroft DW, Davis BE. Mechanisms of airway hyperresponsiveness. J Allergy Clin Immunol 2006; 118: 551-559.

7 Leckie MJ, ten Brinke A, Khan J, et al. Effects of an interleukin-5 blocking monoclonal antibody on eosinophils, airway hyperresponsiveness, and the late asthmatic response. Lancet 2000; 356: 2144-2148.

8 Finkelman FD, Hogan SP, Hershey GK, et al. Importance of cytokines in murine allergic airway disease and human asthma. J Immunol 2010; 184: 1663-1674.

9 Koike E, Takano $\mathrm{H}$, Inoue $\mathrm{K}$, et al. Carbon black nanoparticles promote the maturation and function of mouse bone marrowderived dendritic cells. Chemosphere 2008; 73: 371-376.

10 Koike E, Takano H, Inoue KI, et al. Pulmonary exposure to carbon black nanoparticles increases the number of antigen-presenting cells in murine lung. Int J Immunopathol Pharmacol 2008; 21: 35-42.

11 Koike E, Inoue K, Yanagisawa R, et al. Di-(2-ethylhexyl) phthalate affects immune cells from atopic prone mice in vitro. Toxicology 2009; 259: 54-60.

12 Koike E, Yanagisawa R, Sadakane K, et al. Effects of diisononyl phthalate on atopic dermatitis in vivo and immunologic responses in vitro. Environ Health Perspect 2010; 118: 472-478. 